\title{
Can we score the millennium goals?
}

\section{NEW YORK}

As world leaders gather in New Yorkthis week to discuss the future of the United Nations' Millennium Development Goals, critics are warning that many of the targets cannot be evaluated scientifically. Unless the goals are peer reviewed and amended to take account of what can actually be measured, they say, the project will fail.

Nearly 150 heads of state met in 2000 and pledged to fight problems ranging from poverty to infectious disease in a historic document called the Millennium Declaration. This was turned into a series of numerical targets with a final deadline of 2015 that are known as the Millennium Development Goals.

The ambitious and concrete-sounding aims captured imaginations and headlines worldwide, and have become symbolic of the global development effort. They include halving the number of people that live on less than a dollar a day and cutting deaths in children under five by two-thirds.

But analysts such as Amir Attaran of the University of Ottowa, Canada, say that without drastic revision, the targets risk being meaningless. "We haven't got the tools in place to measure them," he says.

The UN Statistics Division currently keeps tabs on 48 'indicators', which range from school enrolment numbers to malaria death rates. These are provided by agencies such as the World Health Organization (WHO) and the World Bank, but Attaran argues that the methods used to gather data are scientifically flawed. In the absence of birth and death registries in most African countries, for example, many figures on death and illness are gathered from household surveys. These often use conflicting methods, and do not always acknowledge sources of error or apply statistical tests of significance.

And although surveys may measure some indicators accurately - such as childhood deaths, which parents will remember - others are harder to estimate, such as cases of malaria or deaths in childbirth. For example, if a woman succumbs to fatal bleeding in hospital after giving birth at home, the link may not be recorded.

Attaran warns, in PLoS Medicine, that without accurate baseline figures and ongoing measurements it will be impossible to tell in 2015 whether the millennium goals have achieved anything. He wants independent peer reviewers to assess individual targets and indicators to determine whether they can be measured

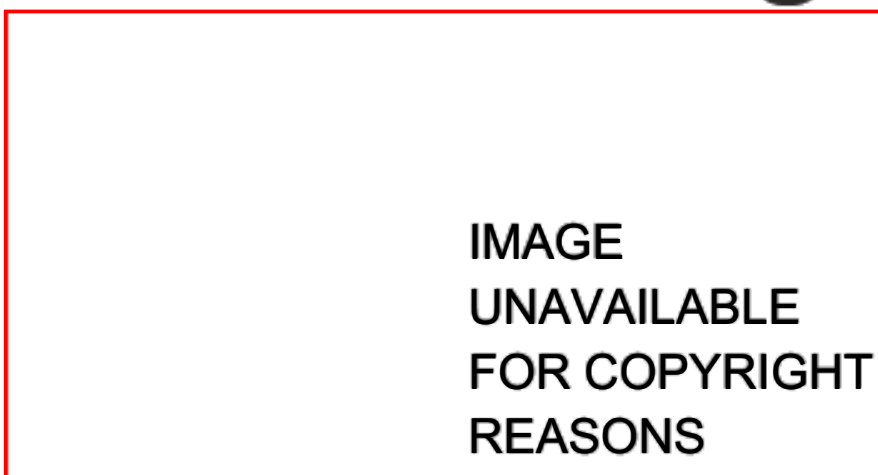

The United Nations has set targets for the relief of human suffering, but progress is hard to measure.

scientifically. If they cannot, he says, the goals should be amended or even abandoned.

Epidemiologists agree that the various indicators could be made more specific, and say leaders should take the opportunity this week to clarify them. "It needs to be talked about now," says Robert Kim-Farley of the University of California, Los Angeles, who used to gather public-health data for the WHO.

"It is relevant to discuss whether we are investing enough in data-collection systems," adds Stefano Bertozzi, director of health economics for the National Institute of Public Health in Cuernavaca, Mexica.

Some UN scientists have expressed concerns like Attaran's. They tried to start a debate last year about how to measure the goals more accurately. But the deputy secretary-general,
Louise Fréchette, deflected them in a message sent to the expert committee in charge of goal statistics. The New York summit "should not be distracted by arguments over the measurement of the millennium development goals or worse, over the different numbers being used by different agencies for the same indicators", she said.

John McArthur is deputy director of the UN Millennium Project - an independent body based in New York that advises the United Nations on the goals. He agrees that the priority for this meeting is simply for nations to affirm their support. He acknowledges that some of the targets are tough to track, but adds, "I don't think that's a reason not to make a concerted effort."

Roxanne Khamsi

\section{Europe backs trials on drugs for kids}

\section{LONDON}

The European Parliament decided last week that drugs authorized for use in children should first be subjected to clinical trials in appropriate age groups.

Although researchers hope extra trials will lead to a better understanding of how medicines work in children, critics are concerned that patent extensions intended to sweeten the decision could delay the availability of cheap drugs.
Many medications given to children in Europe are not licensed for the situations in which they are used. Doctors often take a trial-and-error approach, simply halving the adult dose, for example. But in some cases such drug use has caused side-effects and even fatalities.

There are several reasons why drug companies are reluctant to test their products in children. It is often necessary to develop new equipment and techniques for 


\section{UK embryo licence draws global attention}

Scientists in Britain have been granted permission to perform controversial experiments that will create human embryos using genetic material from three people. Teams carrying out similar research in the United States and China have been forced to shut down their experiments, and say that they hope the UK decision will help push the work forward around the world.

The UK Human Fertilisation and Embryology Authority (HFEA) said on 8 September that it will allow scientists at the University of Newcastle upon Tyne to transfer the nudeus of a fertilized egg into an egg donated by a second woman. The second egg's own nucleus will be removed before the transfer occurs, but it will still contain genetic material in certain structures outside the nucleus. These structures, called mitochondria, generate energy and carry their own genes. So the Newcastle scientists will be creating embryos that contain genes from three people: the biological mother, the biological father and an unrelated egg donor. That makes the experiments highly controversial.

The embryos that will be created in Newcastle will not be transferred into women. But advocates of the technique say that if the experiments work, they could eventually prevent mothers from passing on diseases caused by mitochondrial defects to their children.

Similar experiments were being done in the United States by James Grifo, a reproductive endocrinologist at New York University Medical Center. But in the late 1990s the US Food and Drug Administration (FDA) halted Grifo's experiments after he had created only a few embryos, because it was worried that the health of the fetuses could not be guaranteed. Grifo's postdoctoral fellow, John Zhang, con- tinued the experiments in China, where altered embryos were transferred into two patients before an international outcry shut those experiments down too. Grifo, who has since been pleading with the FDA to allow him to restart the experiments, told Nature that he is encouraged by the HFEA's decision.

${ }^{\alpha} I^{\prime} \mathrm{m}$ glad that at least one country in the world is pioneering and smart enough to do this, and hopefully it will help patients with mitochondrial diseases," Grifo says.

He predicts that the British move will eventually spur action elsewhere, including in the United States. "Once there's some semblance of success over there, they'll say 'OK, now we can do it.' Traditionally, that's how things go."

More than 30 children have already been born thanks to a related technique that is used to boost fertility. The method does not involve nuclear transfer - instead, scientists transfer some of the cytoplasm that surrounds a cell's nucleus from a donor egg to the fertilized egg. But that method has also been halted in the United States, leaving the Newcastle researchers at the head of the field, for the moment at least.

Erika Check

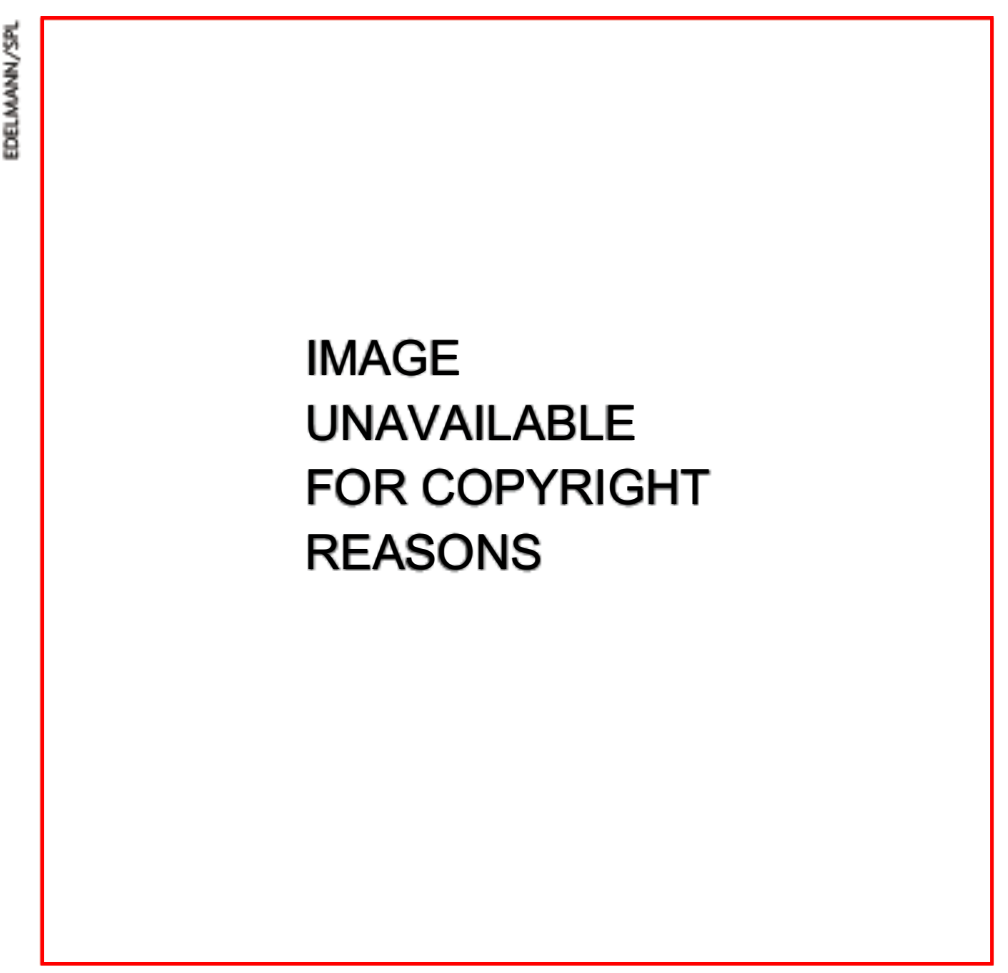

Egged on: researchers in Newcastle will be allowed to createan embryothat contains genes from three people. use on children. And there are sticky ethical issues, such as deciding who gives informed consent when parents are divorced, or what happens when the parents say one thing and the child another.

But the main obstacle, says Sharon Conroy, a paediatric pharmacologist at the University of Nottingham,UK, is the time and money it takes to do the extra tests. Especially as children are relatively healthy, so pharmaceutical companies do not stand to gain much from investing in research on drugs for them.

As an incentive to companies, the
European Parliament and the Council of Ministers are supporting a six-month extension on existing patents, similar to measures offered by the US Food and Drug Administration since 1998.

The European Generic Medicines Association supports the directive in principle, but says the extension may delay the provision of affordable medications for those in financial need.

Mark Schreiner, chairman of the Committees for the Protection of Human Subjects at the Children's Hospital of Philadelphia, points out that the equivalent regulation in the United States has been of tremendous benefit to research. "We've learned how different children are from adults," he says. For example, Viagra is good for treatinglung conditions in children. "We never would have discovered this if drug companies had not been required to carry out rigorous tests with kids," he says.

The parliament's vote is a major step towards enforcing the regulation legally. The proposal was first put forward last September and is expected to become law when the parliament next meets, in 2006. Jennifer Wild 